\title{
A importância do moderador para a educação da oralidade: uma proposta de trabalho com gênero debate público
}

\author{
Bruno Defilippo Horta ${ }^{1}$ \\ Priscila Fernandes Sant'Anna ${ }^{2}$ \\ Universidade Federal de Juiz de Fora
}

Resumo: O ensino de língua materna no Brasil vem passando por um processo de inversão de valores quanto aos papéis assumidos em sala de aula por alunos e professores. Estes encontram dificuldades para se colocar na condição de voz majoritária no ambiente de ensino em virtude da desvalorização de sua profissão, das condições precárias para executar sua função de educadores, agravadas pela carência de formação continuada através da capacitação para ampliar e aperfeiçoar seus conhecimentos e práticas educacionais. Por sua vez, os alunos encontram-se inseridos em uma realidade de dissolução dos valores e ausência de noções e princípios básicos de convivência em espaços coletivos, em razão do crescente distanciamento dos pais no processo de inserção de seus filhos em práticas educacionais permeadas pelas noções de limite e respeito ao espaço do outro. Nesse sentido, em conformidade com as ferramentas da Linguística Interacional (SELTING; COUPERKUHLEN, 2001) e com os pressupostos de Análise da Conversa Etnometodológica e da Sociolinguística Interacional, este artigo tem como objeto de estudo o gênero debate público, motivado pela necessidade de uma (re)educação da oralidade no que tange ao ensino de Língua Portuguesa nas escolas brasileiras. Tendo como base os escritos de Miranda (2005) sobre tal problemática e a partir das teorias dos gêneros textuais presentes em Marcuschi (2002) e Dolz, Schneuwly e Pietro (2004), desenvolveu-se uma proposta de trabalho para o gênero escolhido. Em sua produção final, realizou-se um debate que foi gravado em áudio e, em seguida, transcrito com base em SSJ (1974, citado por GAGO, 2002). Assim, verifica-se como os participantes, atores sociais, agem nessa situação real de fala-em-interação ao realizarem o gênero debate público.

Palavras-chave: Sociolinguística Interacional. Fala-em-interação. Gênero debate público.

\section{Introdução}

O ensino no Brasil, como um todo, vem passando por um processo de vivência de uma realidade cada vez mais frequente no que diz respeito à relação estabelecida entre professores

\footnotetext{
1 Possui graduação em Letras (2007), especialização em Ensino de Língua Portuguesa (2008) e mestrado em Educação (2012) pela Universidade Federal de Juiz de Fora. Seus estudos concentram-se nas áreas da educação da oralidade e da variação linguística na escola, tendo inclusive um capítulo publicado no livro Dos dialetos populares às variedades cultas: a sociolinguística na escola (2011), de autoria da professora Lucia F. de Mendonça Cyranka.

2 Possui graduação em Letras (2007), especialização em Ensino de Língua Portuguesa (2008) e mestrado em Linguística (2011) pela Universidade Federal de Juiz de Fora. Atualmente é doutoranda em Linguística pela mesma instituição. Seus estudos concentram-se na área de Linguagem e Interação, na qual investiga a relação entre o Discurso e as Profissões, com ênfase na intervenção de terceiras partes em situações de conflito e no discurso institucional.
} 
e alunos no que tange aos papéis assumidos por esses atores em sala de aula. No caso dos professores de língua portuguesa, pela carga de responsabilidade atribuída a esses por serem aqueles que têm a responsabilidade de ensinar regras e procedimentos do "bem falar" e do "bem escrever", podemos dizer que essa realidade é ainda mais intensa. De um lado, os docentes enfrentam dificuldades cada vez maiores para se colocar na condição de voz prevalecente no ambiente de ensino em virtude da desvalorização de sua profissão, das condições precárias para executar sua função de educadores, agravadas pela carência de formação continuada através da capacitação para ampliar e aperfeiçoar seus conhecimentos e práticas educacionais. Por sua vez, os alunos encontram-se inseridos em um contexto de distorção de valores e ausência de princípios básicos de convivência em espaços coletivos, muito em função do crescente distanciamento dos pais no processo de inserção de seus filhos em práticas educacionais permeadas pelas noções de limite e respeito ao espaço do outro. Isso se reflete em sala de aula pela distorção do uso da oralidade no espaço escolar, com os professores perdendo o posto de condutores das práticas de uso da fala para os estudantes, que falam quando bem entendem, não aceitam interferências no momento de suas falas e chegam por vezes a situações extremas de agressões verbais e até mesmo físicas contra os docentes.

Uma prática de ensino que pode colaborar muito para a melhoria da postura dos alunos em relação ao uso da oralidade nas diversas instâncias de uso dessa modalidade é o trabalho com o gênero debate público (DOLZ; SCHNEUWLY; PIETRO, 2004). A ideia de trabalhar em torno do debate público e das capacidades argumentativas dos alunos faz-se importante em razão desse gênero possuir uma função significativa em nossa sociedade quanto ao uso adequado da oralidade, pois está claramente incluído nas formas orais de comunicação. Por essa razão, é capaz de desenvolver nos discentes uma série de competências privilegiadas nesse modo de comunicação: garantia do espaço de fala para os participantes, escuta do outro, capacidade de retomada do discurso no momento adequado, entre outras competências.

No contexto desse trabalho com o gênero debate público, uma figura assume um papel fundamental para a manutenção da ordem quanto às realizações das falas dos participantes: o moderador ${ }^{3}$. Cabe a ele assegurar o direito à fala concernente aos participantes, bem como garantir o espaço para que esses sejam também ouvidos, sem interferências ou interrupções, explicando as regras que deverão ser seguidas e as punições decorrentes do descumprimento a essas. Com o intuito de garantir que as diferentes opiniões defendidas sejam realizadas de

3 Neste caso, por uma questão de adequação lexical, adotaremos o termo moderador, mas o concebemos com características e funções semelhantes ao do mediador de conflitos.

SOLETRAS - Revista do Departamento de Letras da FFP/UERJ

Número 31 (jan.-jun. 2016)

ISSN: 2316-8838

DOI: 10.12957/Soletras.2016.22667 
maneira equânime e legítima, o moderador deveria abster-se de valores e convicções pessoais, evitando que esses interfiram no seu modo de conduzir o debate.

Muito se fala do professor como moderador em sala de aula, porém desenvolver a figura do aluno como facilitador da comunicação no ambiente de ensino é um trabalho em que podem ser desenvolvidas as habilidades sociocomunicativas dos estudantes. Mais do que isso, pode prepará-los para que, como atores da sua própria realidade, possam, através das suas próprias iniciativas, encontrar soluções e entendimentos para as questões conflituosas que surgirem durante um período letivo. Dessa maneira, os alunos poderiam ter o poder de tomada de decisões em suas mãos, sem haver a necessidade de transferir as soluções de suas demandas para outras figuras dentro da instituição escolar, como professores, coordenadores e até mesmo o corpo diretivo.

Na esteira desse contexto de relevância da atuação do aluno como moderador no ambiente da sala de aula, este artigo traz os resultados de uma proposta de trabalho com o gênero debate público regrado. Centramos o enfoque na atuação do moderador como agente capaz de facilitar o diálogo, bem como, no âmbito do gênero debate, de manter a ordem e garantir o espaço de fala entre os participantes. O intuito é o de desenvolver a educação da oralidade dos alunos, com o objetivo de demonstrar a importância dessa prática para que assim possam ter uma melhora efetiva nos seus comportamentos nas diversas situações comunicativas do dia a dia.

\section{Aporte teórico}

\subsection{Gêneros textuais, oralidade e ensino}

Como referenciais teóricos no âmbito da tríade oralidade, ensino e gêneros textuais, tomamos como apoio as noções de Marcuschi (2007) e de Scheneuwly e Dolz (2004) sobre gêneros textuais como norteadoras para o ensino de Língua Portuguesa na escola. Baseamonos também na defesa da importância da educação da oralidade feita por Miranda (2005) e nas diretrizes para o desenvolvimento de um trabalho com o gênero debate público arroladas por Dolz, Schenewly e Pietro (2004).

Adotamos aqui a concepção de linguagem como forma de interação na sociedade, ou seja, como um instrumento de mediação entre o indivíduo e os diversos papéis sociais que ele assume nas situações comunicativas das quais participa. Dentro dessa perspectiva, a 
linguagem é tida como uma forma de ação conjunta entre falantes de uma mesma cena de comunicação.

Em consonância com essa concepção, está o ensino de língua a partir dos gêneros textuais. Por conta disso, os conceitos de gênero e tipo textual apontados por Marcuschi (2007) ganham caráter relevante em uma proposta como esta. De acordo com o autor, já se tornou trivial a ideia de que os gêneros textuais são fenômenos históricos, densamente vinculados à vida cultural e social. Além disso, são resultados do trabalho coletivo cotidiano, vide sua contribuição para estabilizar e ordenar as atividades comunicativas do dia-a-dia, sendo ainda "entidades sociodiscursivas e formas de ação social incontornáveis em qualquer situação comunicativa" (MARCUSCHI, 2007, p. 19).

Para Marcuschi (2007), a relevância mais marcante quanto ao tratamento dos gêneros textuais reside particularmente no campo da Linguística Aplicada, em especial no ensino de língua, uma vez que se ensina a produzir textos e não enunciados soltos. Portanto, em sala de aula, os gêneros podem ser tratados de modo a levar os alunos a produzirem os mais diversos eventos linguísticos, tanto orais como escritos, pois, além de constituir um exercício instrutivo, possibilitam também a prática da produção textual. Nada do que fazemos linguisticamente estará fora de ser realizado em algum gênero, logo tudo o que fizermos linguisticamente pode ser tratado num ou noutro gênero.

Scheneuwly e Dolz (2004), assim como Marcuschi (2007), defendem o ensino de língua pautado na noção de gêneros. Dessa forma, expõem os primeiros esboços de uma investigação, baseada na noção de gêneros, realizada por eles na Suíça francófona. Tal investigação surgiu de uma demanda expressa não só pelos professores, mas também pela instituição escolar para o ensino da expressão oral e escrita na escola obrigatória, que no Brasil equivale ao Ensino Fundamental.

A concepção de ensino com gêneros proposta por Dolz e Schneuwly (2004), sobretudo no que concerne ao trabalho com gêneros orais na sala de aula, se confirma em Miranda (2005). A pesquisadora defende a orientação em relação às práticas de oralidade em instâncias públicas e privadas como um caminho a ser seguido pela educação linguística. A falta de uma postura adequada nas cenas de convívio social nas instâncias públicas e privadas de interação aponta para a necessidade de uma revisão dos padrões de oralidade vigentes na sociedade. Em casa, a televisão e o computador são priorizados em detrimento das conversas e das interações sadias entre os membros da família, trazendo como consequência uma sobreposição infindável de vozes que não se entendem. Em relação à escola, especificamente, Miranda 
(2005, p. 163) salienta que a solução encontrada é a adequação à indisciplina com a inauguração da "pedagogia do barulho", na qual o professor que se destaca é aquele disposto a desempenhar o papel de "animador cultural".

Ainda conforme Miranda (2005, p. 164), tudo isso resulta na falta de "regulação de condutas interacionais e linguísticas" que afetam as relações na família e na escola. Perdeu-se a legitimidade entre os papéis de pais e filhos, professores e alunos no meio desse caos. É preciso que se entenda que a existência de papéis sociais nas mais diversas molduras discursivas faz parte da herança cultural adquirida por um povo.

\subsection{A análise da conversa etnometodológica (ACe)}

A Análise da Conversa Etnometodológica (doravante ACe) assume que a linguagem é fundadora da vida em sociedade, já que é por ela que as pessoas interagem. Dessa forma, admite-se que a conversa é fundamental na constituição do mundo social, uma vez que, através dela, as tarefas cotidianas mais práticas são realizadas, como participar de uma reunião de trabalho, ir ao cinema, conversar com os amigos, assistir a uma palestra, entre outras (COULON, 1995).

A conversa espontânea é considerada o gênero básico de linguagem em uso, do qual outros gêneros especializados derivam, como uma modificação daquele. Por isso, ela é vista como a "pedra sociológica fundamental" (SACKS; SCHEGLOFF; JEFFERSON,1974 apud GAGO, 2005).

Quanto às unidades linguísticas estudas na $\mathrm{ACe}$, o turno conversacional ou turno de fala é o organizador dos jatos de linguagem em uso no discurso oral. Em poucas palavras, os turnos representam a vez de cada um ter a palavra na fala (SACKS; SCHEGLOFF; JEFFERSON, 1974 apud GAGO, 2005). Na perspectiva dos turnos de fala, Sacks, Schegloff \& Jefferson (1974) apontaram alguns fatos relativos à conversa espontânea que estão na base da descrição do funcionamento dos turnos de fala. Dentre eles, pode-se destacar: 1) uma pessoa só fala por vez; 2) ocorrências de mais de um falante por vez são comuns, mas breves; 3) transições de um turno para o outro se dão sem intervalo de tempo e sem sobreposição; 4) a ordem dos turnos não é fixa, mas é variável; 5) o tamanho do turno não é fixo, mas variável; 6) a extensão da conversa não é especificada de antemão, nem sobre o que se fala; 7) os turnos são construídos por unidades de tipo específico, entre outros. 
No que se refere à especificidade dos turnos conversacionais, é importante destacar que as unidades de fala concretas que ocupam os turnos são as unidades de construção de turno, as UCTs (GAGO, 2005, p. 64). Essas, conforme dito anteriormente, podem ser de tipos diferentes: 1) lexical, compostas de uma só palavra; 2) sintagmática, correspondente à ideia de sintagma (nominal, verbal, etc.); 3) clausal, cuja característica é possuir um único núcleo verbal; e 4) sentencial, com mais de um núcleo verbal. As UCTs são profundamente significativas para os participantes da interação.

Nossa proposta de trabalho utiliza as ferramentas da Análise da Conversa Etnometodológica por ser ela voltada para a análise de dados reais de fala-em-interação.

\subsection{Mediação de conflitos e mediação escolar}

Neste ponto, cabe esclarecer que, embora não haja sistematizadas teorias sobre "moderação de debates", concebemos o perfil do moderador tal como é concebido o mediador de conflitos. No caso do presente artigo, não se trata de trazer propostas de mediação de conflitos na escola, e sim de apresentar uma proposta pedagógica para o trabalho com a educação da oralidade em sala de aula, por meio do trabalho com o gênero debate público e do estudo da importância do moderador no âmbito desse gênero textual.

Segundo Sales e Alencar (2004, p. 2), “a escola é um lugar onde diariamente convivem pessoas com diferentes características, educações, religiões e personalidades. Entre tantas diferenças é natural que surjam divergências das mais diversas espécies”. Sendo assim, faz-se indispensável uma saudável gestão dos problemas que por ventura surjam a fim de que "a harmonia e o respeito estejam presentes no ambiente escolar e não interfiram no processo de ensino-aprendizagem".

De acordo com as autoras, quando a medição é efetivada no interior dos locais de ensino, ela é chamada de "mediação escolar". Nesse cenário, “a base da mediação escolar é a mesma - diálogo e solidariedade humana -, apenas foi adaptada para ser desenvolvida dentro das escolas, de acordo com suas características" (SALES; ALENCAR, 2004, p. 3). Aqui, a vivência como mediadores pelos próprios atores escolares pode ser importante no que tange à resolução dos conflitos existentes nas situações que permeiam a mediação.

Em consonância com essa proposta de mediação na escola, Cereja e Magalhães (2005) sugerem o trabalho com o gênero debate regrado público e definem quais os princípios e 
R E V I S T A Ensino - N. 31-2016.1-Bruno Defilippo

Priscilla Fernandes Sant'Anna

procedimentos para a realização de um debate em democrático, o qual deve contar com um espaço adequado ao número de participantes, debatedores e um moderador.

A respeito do moderador, afirmam que deve ter algumas posturas fundamentais, tais como: posicionar-se "em pé na sala [...] de modo que possa ser visto por todos"; utilizar "expressões como: "Vamos ouvir a opinião de fulano, ou 'Fulano, sua vez" ao passar a palavra para os debatedores; lembrar "as regras previamente estabelecidas" para o debate; interferir "sempre que houver ruídos ou conversas paralelas na sala que atrapalhem o andamento dos trabalhos" (CEREJA; MAGALHÃES, 2005, p. 117).

\section{Metodologia}

Este trabalho é vinculado à tradição de pesquisa qualitativa e interpretativa (MOITA LOPES, 1994). Essa perspectiva permite uma abordagem que considere os significados, os motivos, as crenças, os valores e as ações dos indivíduos expressos em suas relações.

A intervenção do pesquisador quanto ao ensino de língua em sala de aula (MOITA LOPES, 1994) deve se dar pela sua atuação não apenas como pesquisador-observador apenas, mas também pela intervenção no processo de aprendizagem, com o intuito de realizar um processo de construção mútua dos saberes que busque tornar os alunos sujeitos agentes da construção de seu próprio conhecimento.

Para verificarmos a apropriação do gênero debate público e com o propósito de trabalhar através de uma prática inserida nos moldes da pesquisa-ação, organizamos uma ação por meio da proposta de um trabalho em grupo com foco no uso da oralidade que culminou com um debate em sala de aula. Realizamos essa intervenção em uma turma que faz parte de um projeto de Educação de Jovens e Adultos do colégio de aplicação da Universidade Federal de uma cidade do interior de Minas Gerais.

O tema por nós escolhido a ser debatido foi a Lei 11.705, conhecida como "Lei Seca", por se tratar de um assunto polêmico, muito evidente na mídia e, por isso, gerador de muitas discussões e controvérsias. Visando à realização do gênero em questão, os alunos tiveram a possibilidade de fazer parte de um dos dois grupos que iriam debater o tema ou do grupo que iria avaliar o desempenho dos debatedores, havendo, ainda, um (a) aluno (a) que participaria no papel de moderador (a), sendo que os discentes teriam a liberdade de escolher como gostariam de participar do debate. Adotamos essa postura a fim de pôr em prática o ideal defendido nesta metodologia de tornar o aluno sujeito agente de sua própria história, cujas 
R E $\quad$ I $\mathbf{S}$ T A Ensino - N. 31-2016.1-Bruno Defilippo

Priscilla Fernandes Sant'Anna

ações e resultados devem ser motivados conscientemente através de suas próprias escolhas. Dessa forma, os alunos puderam escolher entre si com quem gostariam de trabalhar e de que forma participariam daquele momento, dentre as seguintes possibilidades:

- Alunos-debatedores favoráveis à Lei Seca (doravante alunos f1, f2, f3, f4);

- Alunos-debatedores contrários à Lei Seca (doravante alunos c1, c2, c3, c4 e c5);

- Alunos-avaliadores do desempenho dos grupos debatedores (doravante alunos a1 e a2);

- Aluno (a)-moderador (a).

Feitas as escolhas, os grupos se reuniram para um momento destinado à preparação para o debate, uma vez que a especificidade do gênero exige uma preparação prévia dos discentes. Os alunos tiveram acesso a textos jornalísticos, entre artigos de opinião, notícias e textos retirados da internet que tratavam do tema trazendo dados, argumentos e opiniões em relação à "Lei Seca". Essa preparação visou orientá-los quanto à argumentação que iriam utilizar na hora de debater, uma vez que, para se defender uma posição a respeito de um tema qualquer, é preciso apresentar bons argumentos a seu favor. Os discentes foram orientados também com relação às regras de comportamento e postura que deveriam adotar na hora do debate, uma vez que se tratava de um contexto formal de uso da fala em que é necessário saber tanto o momento de falar como o de ouvir.

Para a realização, foi destinada uma aula em seus dois horários. As carteiras foram dispostas de modo a formar uma espécie de círculo, com a moderadora ao centro e os grupos distribuídos a partir do centro, cada um para um lado. O grupo avaliador ficou situado ao fundo, de frente para a moderadora, de onde a plateia, composta por pesquisadores e professores, também assistiu ao debate.

O debate foi gravado em áudio e vídeo e, em seguida, transcrito com base em Gago (2002), que delimita quatro questões de fundamental importância para o tratamento e discussão da transcrição do discurso oral em Análise da conversa Etnometodológica (ACe): “1) a justificativa do modelo da transcrição em Análise da Conversa Etnometodológica; 2) o sistema gráfico a ser adotado; 3) o tratamento das pausas no discurso; 4) o tratamento dos risos" (GAGO, 2002, p. 90).

Em relação à atividade de transcrição, esta deve ser considerada uma atividade analítica e representativa que, por ser "sempre uma nova entidade", pode sofrer problemas de representação geral. Não pode ser considerada um produto acabado, pois depende da audição 
R E V I S T A Ensino - N. 31-2016.1-Bruno Defilippo

Priscilla Fernandes Sant'Anna

humana e dos efeitos do tempo, ambos podendo causar mudanças de interpretação. $\mathrm{O}$ autor destaca a importância da concepção da linguagem como interação para os estudos realizados nessa área - "os seres humanos agem no mundo pela linguagem e usam a linguagem para agir no mundo" (GAGO, 2002, p. 90).

Na perspectiva da ACe, o que está em foco são as ações executadas pelos falantes nas relações sequenciais do discurso. Para tanto, o domínio do conceito de turnos de fala unidade de fala orientadora das sequências conversacionais - é essencial. Um turno de fala projeta uma ação e a execução desta ação torna-se relevante para o próximo turno. Tal evento pode ser exemplificado pelos pares adjacentes, "que projetam ações específicas em respostas: uma pergunta, por exemplo, projeta em resposta uma resposta (...)" (GAGO, 2002, p. 93).

Os símbolos utilizados como modelo de transcrição foram desenvolvidos por Jefferson e encontram-se em Sacks, Schegloff \& Jefferson (1974), podendo ser consultados ao fim deste artigo. Dado o escopo da pesquisa, foram selecionados para análise os trechos do debate que permitem visualizar a atuação da moderadora, no intuito de observar de que modo ela interfere no processo e de que forma suas inserções influenciam a postura dos participantes desse evento.

\section{Análise das tarefas do moderador}

Dentro da proposta de trabalho em torno do gênero oral debate público regrado, o intuito foi analisar três tarefas do moderador no que tange à prática da moderação como um instrumento para a educação da oralidade. Também buscamos identificar de que forma essa prática interacional interfere no desenvolvimento dos alunos em relação à postura de facilitadores de conflitos, vindo a acarretar na promoção de um ambiente escolar saudável.

No âmbito de um gênero como o debate público regrado, a presença do moderador é de suma importância para o desenvolvimento da interação, uma vez que cabem a ele algumas tarefas, como garantir o espaço de fala aos participantes, manter a ordem - não permitindo agressões verbais, ofensas pessoais ou fugas desnecessárias ao tema tratado -, não expressar opiniões a favor de alguma ideia defendida por um dos participantes, entre outras. Diante disso, mostraremos alguns trechos do debate realizado em uma turma de jovens e adultos com o intuito de analisar as tarefas da moderadora e a receptividade quanto à realização dessas tarefas pelos participantes, a fim de apontar caminhos para um sistemático e efetivo trabalho 
da educação da oralidade e do desenvolvimento das habilidades de gerenciamento de conflitos em um ambiente acadêmico-escolar.

A seguir, trazemos a análise de dados referentes às três tarefas exercidas pela moderadora em alguns momentos do debate para que possamos verificar como os participantes, atores sociais, agem nessa situação real de fala-em-interação ao realizarem o gênero debate público.

\section{Primeira tarefa: garantia de mesmo espaço de fala aos participantes}

Agora, passamos à análise da segunda parte do debate, na qual os grupos fizeram perguntas entre si. O turno conversacional da moderadora - linhas 07 e 08 - realiza-se após o da aluna f2, que parece concluir sua participação:

\section{Debate 15/10 (04:07-04:24)}

$\begin{array}{lll}07 & \text { moderadora } & \text { está encerrada a participação dos senhores? os senhores acrescentam } \\ 08 & \text { mais alguma coisa? } \\ 09 & \text { aluna f2 } & (\quad) \\ 10 & \text { moderadora } & \text { bom, a senhora ainda tem dois minutos. } \\ 11 & \text { aluna f3 } & \text { não, não= } \\ 12 & \text { moderadora } & {[\text { sim, }]} \\ 13 & \text { aluna f3 } & {[=(]) \text { nós somos a favor porque realmente vai tirar muitas vidas, ( }} \\ 14 & & \text { ) nossos parentes, } \\ 15 & & (3.0) \\ 16 & \text { moderadora } & \text { está certo então. vamos agora passar para segunda parte desse debate, } \\ 17 & & \text { nessa etapa, os grupos terão a oportunidade de fazer uma pergunta } \\ 18 & & \text { para o grupo oponente, obedecendo uma ordem que estabeleceremos } \\ 19 & & \text { por sorteio, o tempo para perguntas será de um minuto, com o tempo } \\ 20 & & \text { de três minutos para resposta, seguindo::- seguido de um minuto para } \\ 21 & & \text { réplica e um minuto para tréplica (.) vamos fazer o sorteio. }\end{array}$

A moderadora, nesse momento, desempenha seu papel de responsável por garantir o espaço de fala aos participantes, de maneira que nenhum grupo seja prejudicado. Nas linhas 07 e 08, observamos sua preocupação em garantir que o tempo para resposta do grupo $\mathrm{F}$ seja efetivamente preenchido. Percebemos ainda que ela tenta evitar momentos em que os participantes de determinado grupo não estejam utilizando o espaço para o propósito do trabalho, o de argumentar a favor de sua posição. Desse modo, a moderadora se certifica se a aluna do grupo a favor terminou sua fala para que, assim, ela possa exercer sua função de 
organizar, dar continuidade ao debate: "está encerrada a participação dos senhores? os senhores acrescentam mais alguma coisa?" (linhas 07 e 08).

Além disso, é possível notar que a aluna-moderadora, a fim de garantir o espaço de fala destinado ao grupo, sinaliza o tempo restante para a resposta: "bom, a senhora ainda tem dois minutos." (linha 10), adequando-se ao trabalho realizado nos módulos da sequência didática, no qual a aluna teve contato com textos que descrevem as tarefas do moderador. Observamos também que a UCT lexical "bom" serve ainda de alerta ao grupo que detém a palavra para que eles utilizem aquele espaço da maneira para a qual ele se destina. Tal alerta é compreendido pela interlocutora, que, imediatamente após a fala da moderadora, retoma o turno, concluindo a participação do seu grupo nessa etapa do debate: "nós somos a favor porque realmente vai tirar muitas vidas, ( ) nossos parentes" (linhas 13 e 14).

\section{Segunda tarefa: condução da continuidade do debate}

Ainda tendo como foco a segunda parte do debate, utilizamos o trecho abaixo a fim de exemplificar a segunda tarefa desempenhada pela moderadora:

\section{Debate 15/10 (04:07-04:41)}

$\begin{array}{lll}07 & \text { moderadora } & \text { está encerrada a participação dos senhores? os senhores acrescentam } \\ 08 & & \text { mais alguma coisa? } \\ 09 & \text { aluna f2 } & (\quad) \\ 10 & \text { moderadora } & \text { bom, a senhora ainda tem dois minutos. } \\ 11 & \text { aluna f3 } & \text { não, não= } \\ 12 & \text { moderadora } & {[\text { sim, }]} \\ 13 & \text { aluna f3 } & {[=(]) \text { nós somos a favor porque realmente vai tirar muitas vidas, ( }} \\ 14 & & \text { ) nossos parentes, } \\ 15 & & (3.0) \\ 16 & \text { moderadora } & \text { está certo então. vamos agora passar para segunda parte desse debate, } \\ 17 & & \text { nessa etapa, os grupos terão a oportunidade de fazer uma pergunta } \\ 18 & & \text { para o grupo oponente, obedecendo uma ordem que estabeleceremos } \\ 19 & & \text { por sorteio, o tempo para perguntas será de um minuto, com o tempo } \\ 20 & & \text { de três minutos para resposta, seguindo::- seguido de um minuto para } \\ 21 & & \text { réplica e um minuto para tréplica (.) vamos fazer o sorteio. }\end{array}$

\section{(4.0) ((mediadora mexendo na caixa com os nomes dos grupos))}

moderadora

o grupo que começa (.) é o grupo contra (.) os senhores tem três minutos por fa- um minuto por favor para a pergunta.

(5.0)

aluno c3 bom, a pergunta que tem aqui para ser feita (.) é se- essa lei, ela foi criada em noventa e sete e ela proibia né, o uso do álcool acima de 


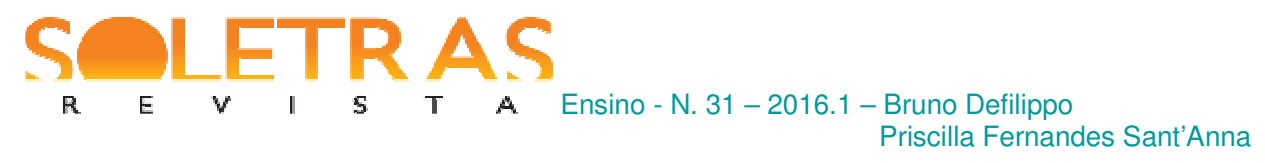

seis decigramas por litro de sangue (.), no caso uma lei que:: não não era respeitada pelos motoristas, por que essa lei não foi respeitada? essa lei agora no caso, vocês acham que essa lei vai ser respeitada já que a fiscalização desde o início foi fraca e incapaz de fazer valer as normas? por que agora ela funcionaria?

Após os três segundos de pausa - (3.0) - (linha 15) e o entendimento da moderadora de que o grupo concluiu sua participação - está certo então. - (linha 16), podemos notar que ela realiza outra tarefa: a condução da continuidade do debate. É a partir de sua fala que se estabelece a continuidade do debate, a qual está diretamente atrelada à condução deste pela moderadora. Essa condução do debate é percebida também no momento em que a moderadora determina o grupo que terá direito ao turno de fala. Tal procedimento vai ao encontro do que afirmam Cereja e Magalhães (2005) sobre as posturas fundamentais esperadas de um moderador, como garantir o turno de falas aos debatedores e fazer a interlocução adequada ao lhes passar a palavra.

Embora não selecione um falante específico para tomar a palavra, é ela a responsável pela transferência dos turnos, ao determinar quem começará fazendo a pergunta referente àquela parte do debate: "o grupo que começa (.) é o grupo contra (.) os senhores tem três minutos por fa- um minuto por favor para a pergunta." (linhas 27 a 29). A partir dessa colocação da moderadora, tem-se o lugar relevante para a transição (LRT), uma vez que é ela quem determina a alocação dos turnos. Após o seu turno de fala, notamos que há uma pausa de cinco segundos - (5.0) - (linha 30), a qual indica que não houve autosseleção por parte de nenhum dos participantes do grupo C. Apenas após esse ínterim, o aluno c3 se autosseleciona a fim de realizar a pergunta que cabe ao seu grupo: "bom, a pergunta que tem aqui para ser feita (.)" (linha 31).

Essas reflexões mostram-nos a importância das referidas tarefas da moderadora para o bom andamento do debate, uma vez que cabe a ela garantir o espaço de fala aos alunos e, ao mesmo tempo, alocar os turnos de fala, assegurando a dinâmica do debate e cumprindo as regras pré-estabelecidas para sua realização (CEREJA; MAGALHÃES, 2005).

\section{Terceira tarefa: esclarecimento das regras do debate}


Agora passaremos à análise do momento destinado para a tréplica feita pelo grupo $\mathrm{C}$ à pergunta do grupo F. O turno da moderadora (linha 41) ocorre logo após a réplica realizada pela aluna f1:

\title{
Debate 15/10 (05:41 - 05:50)
}

\author{
41 moderadora os senhores tem um minuto para a tréplica. \\ 42 aluna c4 ( ) como o motorista vai ser recompensado (.) pela:: perda de \\ 43 tempo? \\ 44 moderadora nã-não é a pergunta senhora, é:: é comentar (.) é uma tréplica. \\ 45 \\ 46 aluna c4 os policiais ( ) detector, se o motorista não se encontra \\ 47 embriagado, através do olhar, como os policiais podem é:: tirar uma \\ $48 \quad$ pessoa do seu trajeto (.) [por uma simples] suspeita né?
}

49

50

Nessa parte do debate, a moderadora desempenha uma relevante tarefa, salientada inclusive por Cereja e Magalhães (2005), que é lembrar as regras previamente estabelecidas para esse contexto comunicativo. Ao anunciar o momento da tréplica, a moderadora assegura ao grupo o direito de fazer um comentário quanto à réplica feita em um momento anterior. Porém, a aluna c4 faz uma pergunta para o outro grupo, demonstrando um desconhecimento no que diz respeito à noção de tréplica: "como o motorista vai ser recompensado (.) pela:: perda de tempo?" (linhas 48 e 49).

Diante disso, a moderadora retifica a fala da aluna através de um reparo em terceira posição, esclarecendo para que serve a tréplica em um debate, ao dizer "nã-não é a pergunta senhora, é:: é comentar (.) é uma tréplica.", definindo, assim, o que é uma tréplica, no intuito de assegurar o pleno cumprimento das regras estabelecidas no início do debate. Feito esse esclarecimento, a aluna demonstra tê-lo entendido e refaz sua fala no turno seguinte, realizando, de fato, um comentário: "os policiais ( ) detector, se o motorista não se encontra embriagado, através do olhar, como os policiais podem é:: tirar uma pessoa do seu trajeto". (linhas 52 a 55). A aluna-moderadora, ao realizar a tarefa descrita, demonstra ter apreendido o que lhe foi passado durante sua preparação para aquele momento.

É o moderador quem vai assegurar que cada momento seja utilizado adequadamente de acordo com o que está previsto para ele. Essa tarefa nos faz perceber como pode ser importante o trabalho com a mediação na escola. Como afirmam Sales e Alencar (2004), o espaço escolar é o local de convívio diário de pessoas com os mais diferentes perfis, 


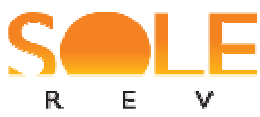

pensamentos e crenças. Dessa forma, a sala de aula pode se constituir como espaço ideal para uma proposta voltada para a educação da oralidade a partir do instante em que noções de respeito às regras sejam trabalhadas, pois demonstram aos alunos que existem algumas molduras sociais, em determinados contextos comunicativos, que devem ser respeitadas.

\section{Considerações finais}

A proposta com a qual trabalhamos, cujos resultados apresentamos neste artigo, nos mostra o quão importante pode ser a reflexão quanto aos papéis assumidos por docentes e discentes dentro do ambiente escolar, em especial na sala de aula. Notamos uma especial relevância para o desenvolvimento de um trabalho sistemático e profundo com as práticas de oralidade na escola a fim de que os alunos tenham consciência de que existem situações em que se deve apenas ouvir, outras nas quais se pode falar livremente e, ainda, outras em que se deve falar, mas também escutar, sabendo-se o momento certo para cada uma dessas ações.

De uma forma geral, foi possível perceber que, no decorrer das atividades, os alunos sentiram-se estimulados a participar de um momento no qual trabalhariam o aperfeiçoamento de suas competências sociocomunicativas em um contexto formal de uso da oralidade. Cada nova descoberta, cada nova habilidade argumentativa que iam desenvolvendo, fazia-os adquirir confiança para empreender sua própria caminhada no uso da língua.

Trabalhar a prática da moderação em sala de aula é um processo que pode ajudar os estudantes a se tornarem sujeitos capazes de facilitar a comunicação em diversas esferas sociais, em especial no ambiente escolar. Ao mesmo tempo, ao participar de um debate, os alunos podem ter uma valiosa oportunidade de pôr em prática os conhecimentos adquiridos no trabalho realizado com um gênero oral.

Em uma sociedade cada vez mais caracterizada pela falta de contato com contextos formais de uso da modalidade oral da língua, propostas que visem a aperfeiçoar as competências comunicativas dos educandos para agirem nessas situações de interação fazemse cada vez mais importantes. Dessa forma, o trabalho com o gênero debate público regrado foi fundamental no que se refere à contribuição para a (re)educação da oralidade dos alunos com os quais trabalhamos nesta pesquisa. É fundamental que qualquer projeto de ensino cujo objetivo seja capacitar o aluno quanto à apropriação do discurso como forma de inserção social esteja alicerçado em trabalhos com os gêneros textuais. 


\section{Referências}

CEREJA, W. R; MAGAlhães, T. C. Português: linguagens. Vol. único. 2. ed. São Paulo: Atual, 2005.

COULON, A. Etnometodologia, Petrópolis, RJ: Vozes, 1995.

DOLZ, J; SCHNEUWLY, B. Gêneros e progressão em expressão oral e escrita - elementos para reflexões sobre uma experiência suíça (francófona). In: Gêneros orais e escritos na escola. Campinas, SP: Mercado de Letras, 2004.

DOLZ, J; SCHNEUWLY, B; PIETRO, Jean-François de. (2004) Relato da elaboração de uma seqüência: o debate público. In: DOLZ, J; SCHNEUWLY, B. Gêneros orais e escritos na escola. Trad. de Roxane Rojo e Glaís Sales Cordeiro. Campinas, SP: Mercado de Letras, p. 247-278.

GAGO, P. C. A organização sequencial da conversa. Revista Calidoscópio, v. 3, n. 2, p. 6173, 2005.

GAGO, P. C. Questões de transcrição em análise da conversa. Revista Veredas, Juiz de Fora, MG, v. 6, n. 2, jul.-dez. 2002.

MARCUSCHI, L. A. Gêneros textuais: definição e funcionalidade. In: DIONISIO, A. P; MACHADO, A. R; BEZERRA, M. A. (Orgs.). Gêneros textuais e ensino. 5. ed. Rio de Janeiro: Lucerna, 2007.

MIRANDA, N. S. Educação da oralidade ou cala a boca não morreu. Revista da Anpoll, Campinas, n. 18, 159-182, jun. 2005.

MOITA LOPES, L. P. Pesquisa interpretativista em Lingüística Aplicada: a linguagem como condição e solução. Revista D.E.L.T.A, v. 10, n. 2, p. 329-338, 1994.

SACKS, H.; SCHEGLOFF, E; JEFFERSON, G. Sistemática elementar para a organização da tomada de turnos para a conversa. Revista Veredas de Estudos Lingüísticos, v. 7, n. 12, p. 0167, 2005. Tradução do original: 1974. A Simplest Systematics for the Organization of Turn Taking for Conversation. Language, v. 50, n. 4, p. 696-735.

SALES, Lília Maia de Morais; ALENCAR, Emanuela Cardoso Onofre de. Mediação de conflitos escolares: uma proposta para a construção de uma nova mentalidade nas escolas. Pensar, Fortaleza, v. 9, n. 9, p. 89-96, fev. 2004. Acesso em: 14 mar. 2016. Disponível em: http://www.unifor.br/notitia/file/1681.pdf. 


\section{ANEXO}

\section{Convenções de transcrição}

[colchetes]

(.)

$=$

distintos.

?

,

?,

:

sublinhado

MAIÚSCULA

o

${ }^{\circ}$ palavras $^{\circ}$

palavra:

palavra:

$\uparrow$

sublinhados.

$\downarrow$

$>$ palavras $<$

<palavras>

$<$ palavras

hhh

(h)

.hhh

(( )) fala sobreposta.

pausa em décimos de segundo.

micropausa de menos de dois décimos de segundo

contiguidade entre a fala de um mesmo falante ou de dois falantes

descida de entonação.

subida de entonação.

entonação continua.

subida de entonação mais forte que a virgula e menos forte que o ponto

de interrogação.

alongamento de som.

autointerrupcão.

acento ou ênfase de volume.

ênfase acentuada.

fala mais baixa imediatamente após o sinal.

trecho falado mais baixo.

descida entoacional inflexionada.

subida entoacional inflexionada.

subida acentuada na entonação, mais forte que os dois pontos

descida acentuada na entonação, mais forte que os dois pontos precedidos de sublinhado.

fala comprimida ou acelerada.

desaceleração da fala.

início acelerado.

aspirações audíveis.

aspirações durante a fala.

inspiração audível.

comentários do analista. 


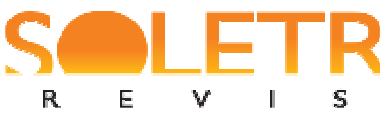

(palavras)

( ) transcrição duvidosa.

transcrição impossível.

th

\title{
The prominence of moderator for orality education: a proposal work with public debate gender
}

\begin{abstract}
The teaching of the Brazilian mother tongue has suffering a process of inversion of values about the roles played in the classroom by students and teachers. These find it difficult to situate themselves in the main voice condition in the education environment due to the devaluation of their profession, the precarious conditions to perform their role as educators, aggravated by the lack of on-training courses to expand and improve their knowledge. On the other hand, students are placed in a reality where basic principles of coexistence in collective spaces are missing and there is no educational practices based on values as respect for the individual. In accordance with the tools of Interactional Linguistics (SELTING; COUPERKUHLEN, 2001) and with the assumptions on the Analysis of Ethno-methodological Conversation and Interactional Sociolinguistics, this article focuses on the study of the public debate genre, motivated by the need of a (re)education of verbal strategies in Portuguese teaching in Brazilian schools. Based on the writings of Miranda (2005) on this issue, and from the theories of textual genres present in Marcuschi (2005) and Dolz, Schneuwly and Pietro (2004), we developed a didactic sequence for the chosen subject. Finally, it was performed a debate which was recorded in audio and transcribed based on SSJ (1974, cited by GAGO, 2002). Thus, we see how participants react in this real situation of speech-in interaction.
\end{abstract}

Key-words: Interactional sociolinguistic. Speech-in interaction. Public debate genre.

Recebido em: 30 de abril de 2016.

Aprovado em: 06 de julho de 2016. 